Article

\title{
A Liquid Chromatography-High Resolution Mass Spectrometry (LC-HRMS) Method for the Determination of Free Hydroxy Fatty Acids in Cow and Goat Milk
}

\author{
Maroula G. Kokotou, Christiana Mantzourani, Asimina Bourboula, Olga G. Mountanea \\ and George Kokotos *(D) \\ Department of Chemistry, National and Kapodistrian University of Athens, 15771 Athens, Greece; \\ mkokotou@chem.uoa.gr (M.G.K.); chrmantz@chem.uoa.gr (C.M.); minabour@chem.uoa.gr (A.B.); \\ olgamount@chem.uoa.gr (O.G.M.) \\ * Correspondence: gkokotos@chem.uoa.gr; Tel.: +30-210-7274462
}

Academic Editors: Pamela Manzi and Mena Ritota

Received: 12 July 2020; Accepted: 27 August 2020; Published: 29 August 2020

\begin{abstract}
A liquid chromatography-high resolution mass spectrometry (LC-HRMS) method for the direct determination of various saturated hydroxy fatty acids (HFAs) in milk was developed for the first time. The method involves mild sample preparation conditions, avoids time-consuming derivatization procedures, and permits the simultaneous determination of 19 free HFAs in a single 10-min run. This method was validated and applied in 17 cow milk and 12 goat milk samples. This work revealed the existence of various previously unrecognized hydroxylated positional isomers of palmitic acid and stearic acid in both cow and goat milk, expanding our knowledge on the lipidome of milk. The most abundant free HFAs in cow milk were proven to be 7-hydroxystearic acid (7HSA) and 10-hydroxystearic acid (10HSA) (mean content values of $175.1 \pm 3.4 \mu \mathrm{g} / \mathrm{mL}$ and $72.4 \pm 6.1 \mu \mathrm{g} / \mathrm{mL}$ in fresh milk, respectively). The contents of 7HSA in cow milk seem to be substantially higher than those in goat milk.
\end{abstract}

Keywords: determination; hydroxy fatty acids; high resolution mass spectrometry; liquid chromatography; milk

\section{Introduction}

Lipids are one of the most important classes of milk components [1,2]. Apart from their role as a source of energy, they contribute to the sensory and physical properties of milk. The majority of lipids in dairy fat are triacylglycerols [3], while small amounts of free fatty acids (FFAs) are also present as a result of the enzymatic hydrolysis of triacylglycerols by lipoprotein lipase and other lipolytic enzymes [4]. Among the numerous fatty acids (FAs) found in milk, long-chain saturated fatty acids (SFAs) are the predominant class [5,6]. However, common unsaturated FAs (mainly mono-unsaturated) as well as short-chain FAs, branched, and odd-chain FAs, trans FAs, and conjugated linoleic acid are also present $[7,8]$.

Various FAs present in milk fat are linked either in a positive or a negative way with human health [9]. For decades, nutritional guidelines have suggested a reduction in the intake of milk SFAs, because these fatty acids have been linked with pathologies such as metabolic syndrome and cardiovascular diseases. This notion is currently in question, and recent scientific studies do not seem to justify such recommendations in a healthy population [10-12]. Most recently, Astrup and colleagues argued that the health effects vary for different types of SFAs and that the composition of the food source is crucially important [13]. For example, higher levels of odd-chain SFAs C15:0 and C17:0 are 
associated with a lower risk of type 2 diabetes (T2D), as shown by a recent large meta-analysis which pooled the findings from 16 prospective cohort studies [14].

The analytical methods, for the determination of free fatty acids (FFAs) in milk have been recently reviewed [6,15]. Gas chromatography-mass spectrometry (GC-MS) analysis is the most popular technique for the analysis of FFAs, after their conversion into their corresponding methyl esters (FAMEs). A high performance liquid chromatography-mass spectrometry (HPLC-MS) method has been reported for the determination of FFAs in food samples, including milk, after derivatization with 2-hydrazinoquinoline [16], while most recently we employed a LC-High Resolution MS (LC-HRMS) method for the quantification of FFAs in milk [17].

The presence of saturated hydroxy fatty acids (SHFAs) in foods has attracted less attention so far. Jenske and Vetter have described the analysis of 2- and 3-hydroxy FAs (2HFAs, 3HFAs) in food samples, and they have determined the concentrations of several 2HFAs and 3HFAs in milk and other dairy products by gas chromatography with electron-capture negative ion mass spectrometry $[18,19]$. Only one report refers to the existence in milk of two different SHFAs possessing the hydroxyl at higher positions of the fatty chain-namely, 10-hydroxystearic acid and 8-hydroxypalmitic acid [20].

Within our project dedicated to the synthesis and study of bioactive lipids, we have a special interest in SHFAs, since such compounds are the key components of a recently identified novel class of anti-inflammatory and anti-diabetic lipids, called the fatty acid esters of hydroxy fatty acids (FAHFAs) [21-23]. However, SHFAs exhibit biological roles and actions by their own right. For example, 9-hydroxystearic acid (9HSA) has been shown to inhibit cell growth in human colon cancer, targeting histone deacetylase-1 [24], and to mediate the switch from proliferation to differentiation in retinal progenitor cells [25]. We have recently developed methods for the synthesis of various SHFAs, including both 9-hydroxy and 3-hydroxy FAs [26,27].

The aim of the present work was the development of a LC-HRMS method for the straightforward and rapid determination of various free SHFAs in milk samples. Such a method may unravel the existence of potential bioactive ingredients in milk that may play a role in human health. We describe herein a method allowing the simultaneous determination of 19 SHFAs in a single 10-min run, avoiding any derivatization step and employing a simple and mild protocol for sample preparation.

\section{Results and Discussion}

\subsection{LC-ESI-MS Data}

Nineteen SHFAs were used in the present study. Eight of them were regio-isomers of hydroxy palmitic acid [2-hydroxypalmitic acid (2HPA), 3-hydroxypalmitic acid (3HPA), 7-hydroxypalmitic acid (7HPA), 8-hydroxypalmitic acid (8HPA), 9-hydroxypalmitic acid (9HPA), 10-hydroxypalmitic acid (10HPA), 11-hydroxypalmitic acid (11HPA), 16-hydroxypalmitic acid (16HPA)], and seven were regio-isomers of stearic acid [2-hydroxystearic acid (2HSA), 3-hydroxystearic acid (3HSA), 7-hydroxystearic acid (7HSA), 8-hydroxystearic acid (8HSA), 9-hydroxystearic acid (9HSA), 10-hydroxystearic acid (10HSA), 12-hydroxystearic acid (12HSA)]. In addition, four 3-hydroxy FAs [3-hydroxycapric acid (3HCA), 3-hydroxylauric acid (3HLA), 3-hydroxymyristic acid (3HMA), 3-hydroxypentadecanoic acid (3HPDA)] were included in the set of compounds tested. The high-resolution mass spectra of these HFAs were recorded in electrospray ionization (ESI) negative mode. The structures of the SHFAs used along with the exact masses of the deprotonated molecules and the retention times observed for each one of them in the chromatographic method are presented in Table 1. The MS/MS spectra of all the 19 analytes in negative ESI mode are also presented in the Supplementary Materials (Figure S1).

We have developed a rapid LC-HRMS method allowing the simultaneous determination of a variety of SHFAs in milk in a 10-min run. The extracted ion chromatograms (EICs) of the analytes in a standard solution $(1 \mu \mathrm{g} / \mathrm{mL})$ are presented in Figure 1. 
Table 1. Hydroxy fatty acid standards used in the chromatographic method.

\begin{tabular}{|c|c|c|c|c|}
\hline Compound & Abbreviation & Structure & $\begin{array}{c}\text { Theoretical } \\
\text { Mass }[\mathrm{M}-\mathrm{H}]^{-}\end{array}$ & $\begin{array}{c}\text { Retention } \\
\text { Time (min) }\end{array}$ \\
\hline 2-Hydroxypalmitic acid & 2HPA & & 271.2279 & 5.57 \\
\hline 3-Hydroxypalmitic acid & 3HPA & & 271.2279 & 5.33 \\
\hline 7-Hydroxypalmitic acid & 7HPA & & 271.2279 & 4.64 \\
\hline 8-Hydroxypalmitic acid & 8HPA & & 271.2279 & 4.49 \\
\hline 9-Hydroxypalmitic acid & 9HPA & & 271.2279 & 4.56 \\
\hline 10-Hydroxypalmitic acid & 10HPA & & 271.2279 & 4.43 \\
\hline 11-Hydroxypalmitic acid & 11HPA & & 271.2279 & 4.39 \\
\hline 16-Hydroxypalmitic acid & 16HPA & & 271.2279 & 4.31 \\
\hline 2-Hydroxystearic acid & 2HSA & & 299.2592 & 6.22 \\
\hline 3-Hydroxystearic acid & 3HSA & & 299.2592 & 5.99 \\
\hline 7-Hydroxystearic acid & 7HSA & & 299.2592 & 5.17 \\
\hline 8-Hydroxystearic acid & 8HSA & & 299.2592 & 5.25 \\
\hline 9-Hydroxystearic acid & 9HSA & & 299.2592 & 5.32 \\
\hline 10-Hydroxystearic acid & 10HSA & & 299.2592 & 5.11 \\
\hline 12-Hydroxystearic acid & 12HSA & & 299.2592 & 5.02 \\
\hline 3-Hydroxycapric acid & $3 \mathrm{HCA}$ & & 187.1340 & 3.06 \\
\hline 3-Hydroxylauric acid & 3HLA & & 215.1653 & 3.90 \\
\hline 3-Hydroxymyristic acid & 3HMA & & 243.1966 & 4.67 \\
\hline 3-Hydroxypentadecanoic acid & 3PDA & & 257.2122 & 5.04 \\
\hline
\end{tabular}

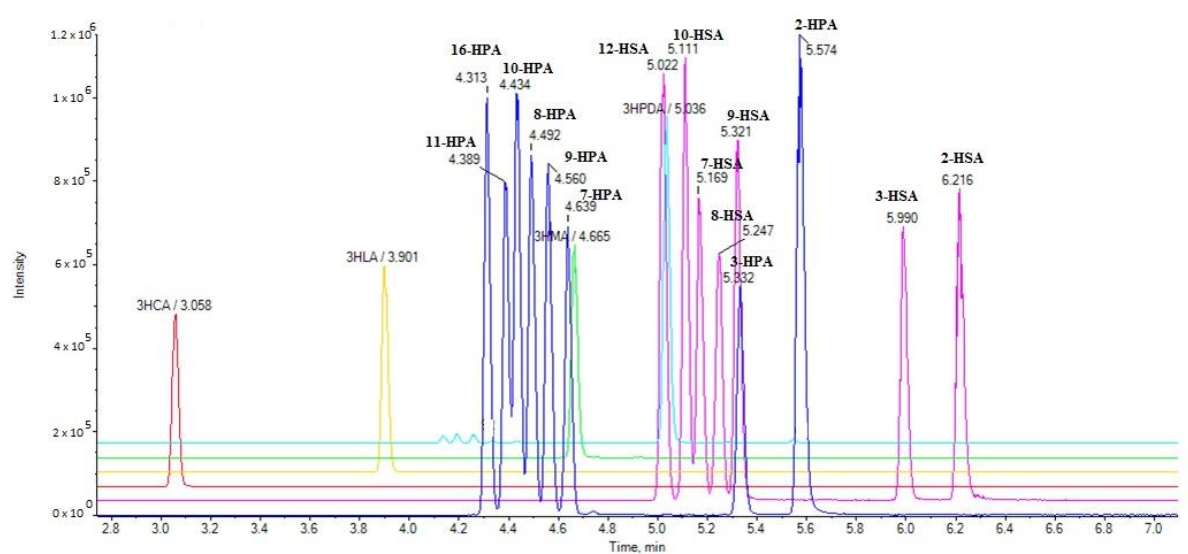

Figure 1. Extracted ion chromatograms (EICs) of hydroxy fatty acids in a standard solution $(1 \mu \mathrm{g} / \mathrm{mL})$. 


\subsection{Method Validation}

Good linearity values ranging from 0.990 to 0.998 were observed for all the analytes. The limits of detection (LOD) and quantification (LOQ) are summarized in Table 2. The limits of detection varied from 0.1 to $0.9 \mathrm{ng} / \mathrm{mL}$, while the limits of quantification ranged from 0.4 to $2.6 \mathrm{ng} / \mathrm{mL}$.

Table 2. Limits of detection (LOD) and quantification (LOQ).

\begin{tabular}{ccc}
\hline Analyte & LOD $(\mathbf{n g} / \mathrm{mL})$ & LOQ $(\mathbf{n g} / \mathrm{mL})$ \\
\hline 2HPA & 0.3 & 0.8 \\
3HPA & 0.5 & 1.4 \\
7HPA & 0.8 & 2.4 \\
8HPA & 0.5 & 1.2 \\
9HPA & 0.6 & 1.7 \\
10HPA & 0.5 & 1.2 \\
11HPA & 0.5 & 1.6 \\
16HPA & 0.9 & 2.6 \\
2HSA & 0.1 & 0.4 \\
3HSA & 0.3 & 0.9 \\
7HSA & 0.4 & 1.1 \\
8HSA & 0.5 & 1.0 \\
9HSA & 0.6 & 1.8 \\
10HSA & 0.4 & 1.1 \\
12HSA & 0.5 & 1.4 \\
3HCA & 0.3 & 1.0 \\
3HLA & 0.5 & 1.4 \\
3HMA & 0.6 & 1.7 \\
3HPDA & 0.6 & 1.9 \\
\hline
\end{tabular}

A simple sample preparation procedure was followed, involving the addition of methanol for protein precipitation. After centrifugation, the supernatant was used for the analysis. For the verification of the accuracy and precision, the guidelines of the EU Commission decision 202/657/EC were followed. The milk samples were spiked at three different concentration levels with three replicates for each fortification level. Satisfactory recoveries, ranging from 80.8 to 109.4 for the low spike level, from 81.4 to 109.1 for the medium spike level, and from 80.8 to 100.5 for the high spike level (Table 3), indicate the accuracy of the proposed method. The matrix factor was calculated as the ratio of the peak response in the presence of a matrix to the peak response in the pure solvents. A matrix factor value $<1$ suggests signal suppression in the samples, while a matrix factor value $>1$ denotes signal enhancement (Table 3). The precision was investigated by means of the relative standard deviation (\%RSD). The \%RSD values that were obtained for the intra-day (RSDr) and inter-day $\left(\mathrm{RSD}_{\mathrm{R}}\right)$ variations ranged from 0.54 to 11.16 and from 0.71 to 13.25 , respectively, depending on the HFAs (Table 3).

Table 3. Accuracy (recovery \%), matrix factor (MF), and precision data (RSD \%) in the spiked milk samples.

\begin{tabular}{cccccc}
\hline Analyte & Spike Level $(\mathbf{n g} / \mathbf{m L})$ & Recovery $(\%)$ & Matrix Factor $(\mathbf{M F})$ & RSD $_{\mathbf{r}}(\mathbf{\%})$ & RSD $_{\mathbf{R}}(\mathbf{\%})$ \\
\hline \multirow{3}{*}{ 2HPA } & 10 & 80.8 & 0.7 & 8.53 & 2.11 \\
& 300 & 101.4 & 0.9 & 10.50 & 8.79 \\
\multirow{3}{*}{ 3HPA } & 500 & 100.5 & 1.0 & 4.06 & 5.12 \\
& 10 & 81.2 & 0.7 & 3.96 & 2.11 \\
& 300 & 96.5 & 0.8 & 7.65 & 11.64 \\
7HPA & 500 & 94.9 & 1.2 & 7.20 & 9.10 \\
& 10 & 95.5 & 0.9 & 4.51 & 4.31 \\
& 300 & 96.1 & 1.2 & 8.78 & 7.65 \\
\hline
\end{tabular}


Table 3. Cont

\begin{tabular}{|c|c|c|c|c|c|}
\hline Analyte & Spike Level (ng/mL) & Recovery (\%) & Matrix Factor (MF) & $\operatorname{RSD}_{\mathrm{r}}(\%)$ & $\mathrm{RSD}_{\mathrm{R}}(\%)$ \\
\hline & 10 & 83.2 & 0.9 & 4.60 & 7.93 \\
\hline \multirow[t]{3}{*}{ 8HPA } & 300 & 107.9 & 1.0 & 4.09 & 5.94 \\
\hline & 500 & 105.1 & 1.1 & 3.21 & 7.63 \\
\hline & 10 & 103.1 & 1.1 & 0.54 & 0.76 \\
\hline \multirow[t]{3}{*}{ 9HPA } & 300 & 109.1 & 1.0 & 5.51 & 8.88 \\
\hline & 500 & 100.00 & 1.3 & 4.96 & 6.21 \\
\hline & 10 & 95.5 & 0.9 & 2.69 & 6.56 \\
\hline \multirow{3}{*}{ 10HPA } & 300 & 94.9 & 0.7 & 4.36 & 10.9 \\
\hline & 500 & 98.1 & 1.1 & 2.54 & 5.61 \\
\hline & 10 & 109.3 & 0.9 & 1.42 & 6.29 \\
\hline \multirow[t]{3}{*}{ 11HPA } & 300 & 90.8 & 0.8 & 5.12 & 6.36 \\
\hline & 500 & 95.3 & 1.2 & 1.11 & 4.32 \\
\hline & 10 & 100.3 & 1.0 & 0.49 & 1.94 \\
\hline \multirow{3}{*}{ 16HРA } & 300 & 96.3 & 0.9 & 5.63 & 7.14 \\
\hline & 500 & 90.8 & 1.2 & 7.94 & 9.21 \\
\hline & 10 & 92.6 & 1.1 & 0.71 & 3.79 \\
\hline \multirow[t]{3}{*}{ 2HSA } & 300 & 88.0 & 0.5 & 9.74 & 13.25 \\
\hline & 500 & 92.5 & 1.3 & 11.10 & 12.73 \\
\hline & 10 & 80.6 & 0.7 & 0.71 & 6.01 \\
\hline \multirow[t]{3}{*}{$3 \mathrm{HSA}$} & 300 & 81.4 & 0.7 & 6.60 & 8.53 \\
\hline & 500 & 96.4 & 1.4 & 11.16 & 13.02 \\
\hline & 10 & 104.9 & 1.2 & 5.14 & 7.03 \\
\hline \multirow[t]{3}{*}{ 7HSA } & 300 & 103.0 & 0.9 & 2.41 & 11.2 \\
\hline & 500 & 88.1 & 0.5 & 9.06 & 12.1 \\
\hline & 10 & 95.4 & 0.9 & 9.38 & 11.55 \\
\hline \multirow[t]{3}{*}{ 8HSA } & 300 & 84.2 & 0.8 & 4.56 & 12.2 \\
\hline & 500 & 94.3 & 1.1 & 3.22 & 8.79 \\
\hline & 10 & 92.6 & 0.9 & 0.27 & 0.71 \\
\hline \multirow[t]{3}{*}{ 9HSA } & 300 & 85.7 & 0.8 & 9.74 & 13.25 \\
\hline & 500 & 90.9 & 1.4 & 9.06 & 10.41 \\
\hline & 10 & 82.8 & 0.9 & 2.41 & 3.37 \\
\hline \multirow[t]{3}{*}{ 10HSA } & 300 & 85.3 & 0.7 & 7.55 & 9.47 \\
\hline & 500 & 92.5 & 0.5 & 6.18 & 9.25 \\
\hline & 10 & 109.4 & 1.1 & 3.37 & 10.12 \\
\hline \multirow[t]{3}{*}{ 12HSA } & 300 & 100.9 & 1.0 & 6.18 & 7.01 \\
\hline & 500 & 101.6 & 1.2 & 3.42 & 5.21 \\
\hline & 10 & 105.9 & 1.1 & 1.36 & 3.21 \\
\hline \multirow[t]{3}{*}{$3 \mathrm{HCA}$} & 300 & 84.3 & 0.8 & 4.37 & 8.62 \\
\hline & 500 & 91.4 & 1.3 & 5.49 & 7.24 \\
\hline & 10 & 89.4 & 0.9 & 4.16 & 4.78 \\
\hline \multirow[t]{3}{*}{ 3HLA } & 300 & 89.7 & 0.8 & 8.62 & 6.07 \\
\hline & 500 & 90.3 & 1.3 & 3.51 & 4.21 \\
\hline & 10 & 90.0 & 0.9 & 1.03 & 1.54 \\
\hline \multirow[t]{3}{*}{ 3НMA } & 300 & 88.1 & 0.8 & 6.99 & 10.92 \\
\hline & 500 & 96.3 & 1.3 & 5.49 & 10.11 \\
\hline & 10 & 82.4 & 0.7 & 1.54 & 4.16 \\
\hline \multirow[t]{2}{*}{ 3HPDA } & 300 & 99.2 & 1.0 & 4.48 & 10.92 \\
\hline & 500 & 96.2 & 1.4 & 0.99 & 5.21 \\
\hline
\end{tabular}

$\mathrm{RSD}_{\mathrm{r}}$ : intra-day relative standard deviation; $\mathrm{RSD}_{\mathrm{R}}$ : inter-day relative standard deviation.

\subsection{Analysis of Samples}

Seventeen cow milk samples and 12 goat milk samples were purchased from the local market and analyzed. The extracted ion chromatograms (EICs) of a cow milk sample (A) and a goat milk (B) sample are shown in Figure 2. The simultaneous determination of 19 SHFAs was achieved in a single 10-min run. The contents of the 19 analytes in milk samples (in triplicate) are summarized in Table 4 , and they are expressed as the $\mu \mathrm{g}$ of HFA per $\mathrm{mL}$ of milk. The integration of the peak areas was 
performed manually using MultiQuant 3.0.2. As Hill et al. discussed [28], in particular cases a manual baseline may be employed for the quantification of the peak areas. The same integration parameters were used in all cases.

A variety of SHFAs were found to be present in both cow and goat milk (Table 4), in addition to 2HFAs and 3HFAs, which have been previously reported as milk fat minor components [18,19]. In cow milk, 11HPA was estimated as the most abundant $(42.9 \pm 4.7 \mu \mathrm{g} / \mathrm{mL})$ among HPAs, followed by 16HPA, 3HPA, 8HPA, 2HPA, 10HPA, and 9HPA at levels varying from 37.2 \pm 5.1 to $14.7 \pm 7.1 \mu \mathrm{g} / \mathrm{mL}$. 7HPA was absent from seven cow milk samples. The most abundant HFAs in cow milk were proven to be 7HSA and 10HSA. Their contents were estimated at mean values of $175.1 \pm 3.4 \mu \mathrm{g} / \mathrm{mL}$ and $72.4 \pm 6.1 \mu \mathrm{g} / \mathrm{mL}$, respectively. 3HSA, 2HSA, and 9HSA were found to be present at levels varying from $33.8 \pm 6.6$ to $20.1 \pm 4.7 \mu \mathrm{g} / \mathrm{mL}$, while 8HSA was absent from all the cow milk samples and 12HSA absent from seven samples.

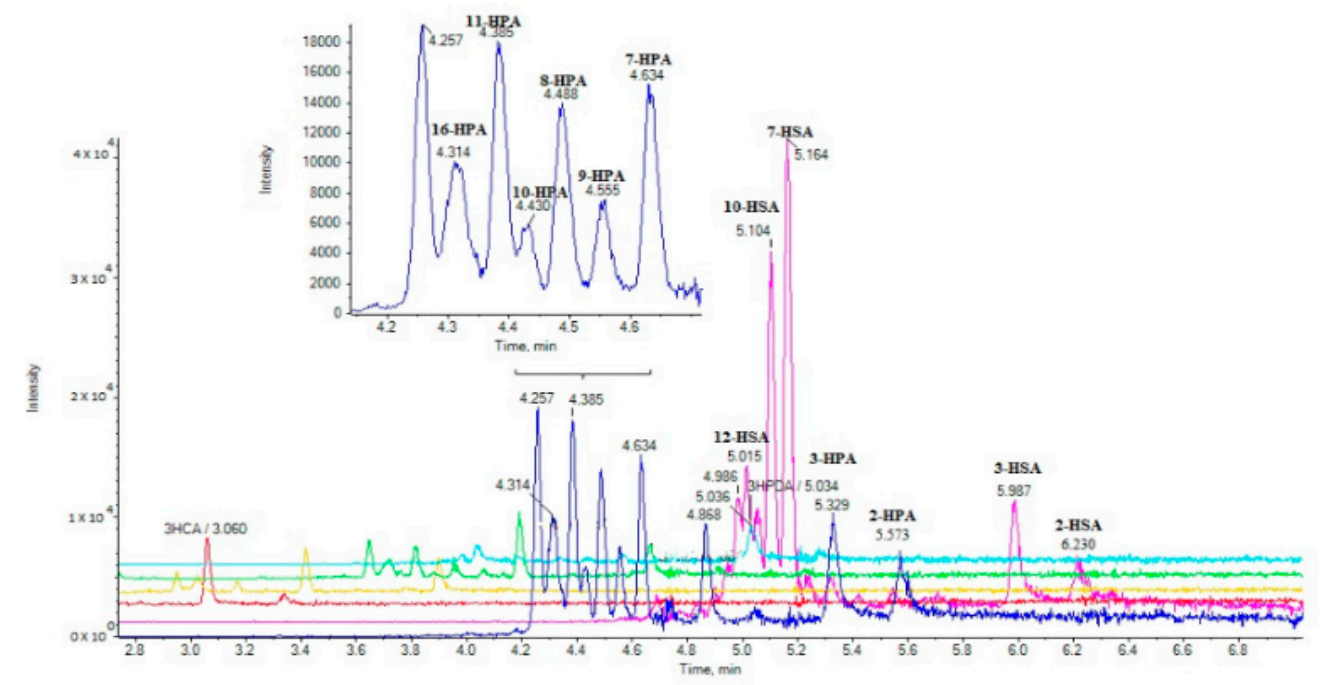

(A)

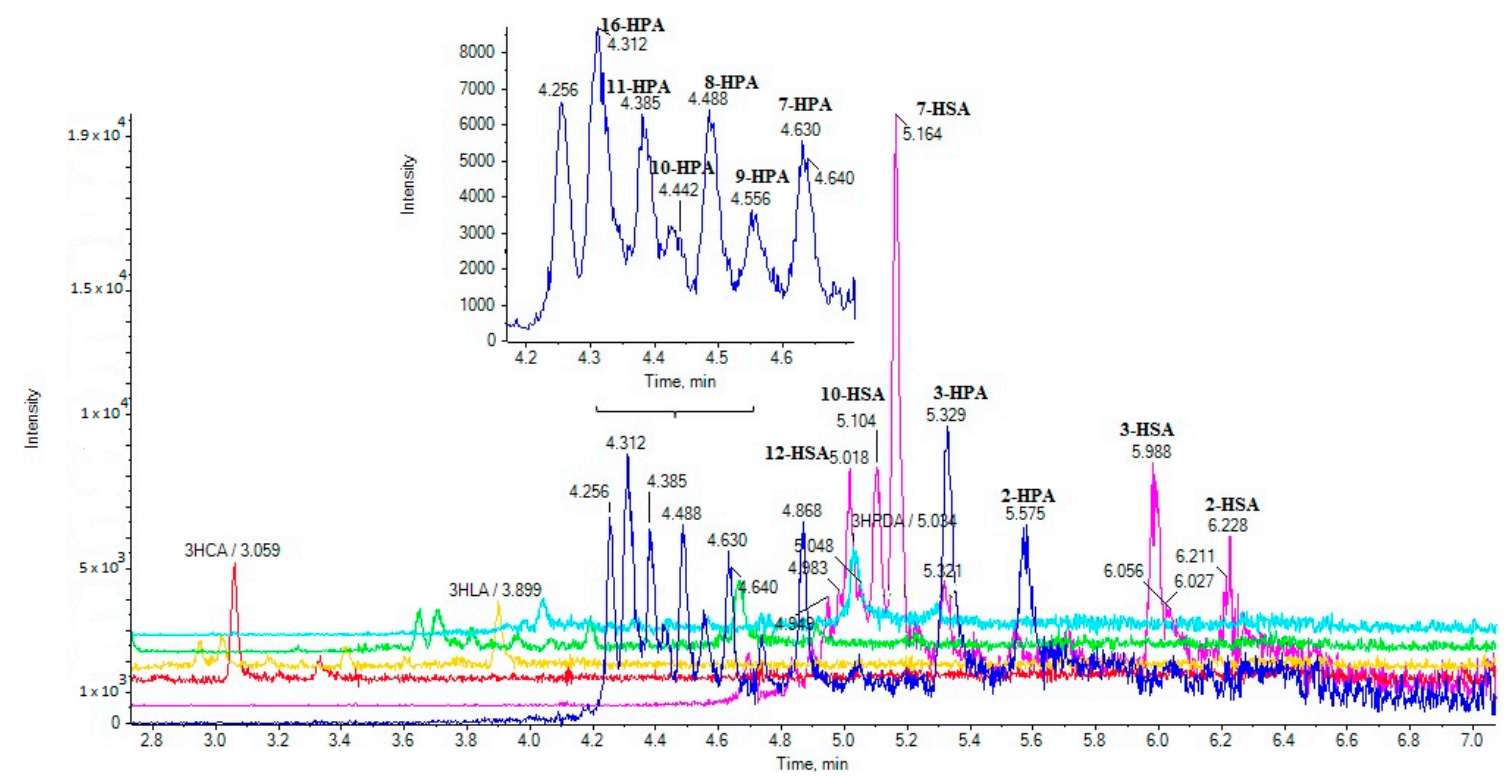

(B)

Figure 2. EICs of the analytes in a cow milk sample (A) and in a goat milk sample (B). 
Table 4. Contents of free hydroxy fatty acids in cow milk and goat milk samples ( $\mu \mathrm{g} / \mathrm{mL}$ fresh milk).

\begin{tabular}{|c|c|c|c|c|c|c|c|c|}
\hline \multicolumn{5}{|c|}{ Cow Milk $(n=17)$, Triplicates } & \multicolumn{4}{|c|}{ Goat Milk $(n=12)$, Triplicates } \\
\hline $\begin{array}{c}\text { Hydroxy Fatty } \\
\text { Acid }\end{array}$ & $\underset{(\mu \mathrm{g} / \mathrm{mL})}{\text { Minimum Value }}$ & $\begin{array}{c}\text { Maximum Value } \\
(\mu \mathrm{g} / \mathrm{mL})\end{array}$ & $\begin{array}{c}\text { Mean Value } \pm S D \\
(\mu \mathrm{g} / \mathrm{mL})\end{array}$ & $\begin{array}{c}\text { Level of } \\
\text { Significance }\end{array}$ & $\begin{array}{c}\text { Minimum Value } \\
(\mu \mathrm{g} / \mathrm{mL})\end{array}$ & $\begin{array}{c}\text { Maximum Value } \\
(\mu \mathrm{g} / \mathrm{mL})\end{array}$ & $\begin{array}{c}\text { Mean Value } \pm \text { SD } \\
(\mu \mathrm{g} / \mathrm{mL})\end{array}$ & $\begin{array}{c}\text { Level of } \\
\text { Significance }\end{array}$ \\
\hline $2 \mathrm{HPA}$ & 8.2 & 40.8 & $22.7 \pm 4.1$ & ** & 9.0 & 27.3 & $19.1 \pm 6.1$ & * \\
\hline $7 \mathrm{HPA}$ & $<\mathrm{LOQ}^{\mathrm{a}}$ & 23.1 & $14.7 \pm 7.1^{b}$ & NS & $<\mathrm{LOQ}^{\mathrm{c}}$ & 5.8 & $2.8 \pm 0.9^{b}$ & $* * *$ \\
\hline $8 \mathrm{HPA}$ & 14.2 & 42.6 & $26.8 \pm 3.5$ & NS & 7.7 & 44.3 & $22.5 \pm 8.0$ & NS \\
\hline 9HPA & 13.2 & 45.6 & $17.6 \pm 5.2$ & $* *$ & 7.5 & 18.8 & $12.8 \pm 3.9$ & NS \\
\hline $10 \mathrm{HPA}$ & 6.2 & 33.1 & $20.7 \pm 4.2$ & NS & 5.2 & 7.8 & $5.8 \pm 1.1$ & $* * *$ \\
\hline $11 \mathrm{HPA}$ & 14.4 & 89.2 & $42.9 \pm 4.7$ & $* * *$ & 6.5 & 18.9 & $13.5 \pm 2.6$ & NS \\
\hline $16 \mathrm{HPA}$ & 15.3 & 82.1 & $37.2 \pm 5.1$ & $* * *$ & 17.1 & 40.8 & $25.1 \pm 5.2$ & $* *$ \\
\hline 2HSA & 10.0 & 51.8 & $23.5 \pm 2.6$ & ** & 5.8 & 32.6 & $20.1 \pm 6.8$ & NS \\
\hline 3HSA & 12.1 & 54.4 & $33.8 \pm 6.6$ & $* * *$ & 12.9 & 38.3 & $25.3 \pm 6.3$ & $* * *$ \\
\hline 7HSA & 38.3 & 378.8 & $175.1 \pm 3.4$ & $* * *$ & 21.5 & 48.0 & $38.2 \pm 8.2$ & $* *$ \\
\hline 8HSA & $<\mathrm{LOQ}$ & $<$ LOQ & $0.5 \pm 0.0^{\mathrm{b}}$ & - & $<$ LOQ & $<\mathrm{LOQ}$ & $0.5 \pm 0.0^{b}$ & - \\
\hline 9HSA & 8.9 & 43.4 & $20.1 \pm 4.7$ & $* * *$ & 6.4 & 10.8 & $8.6 \pm 1.5$ & $* *$ \\
\hline 10HSA & 31.2 & 250.1 & $72.4 \pm 6.1$ & $* * *$ & 18.0 & 75.4 & $39.1 \pm 7.2$ & ** \\
\hline 12HSA & $<\mathrm{LOQ}^{\mathrm{a}}$ & 22.3 & $17.9 \pm 5.3^{b}$ & NS & 5.0 & 11.1 & $9.1 \pm 2.1$ & $* *$ \\
\hline $3 \mathrm{HCA}$ & $<\mathrm{LOQ}^{\mathrm{d}}$ & 18.9 & $7.7 \pm 4.1^{b}$ & $* * *$ & 11.8 & 25.2 & $18.8 \pm 3.8$ & $* * *$ \\
\hline 3HLA & $<\mathrm{LOQ}^{\mathrm{a}}$ & 36.8 & $13.2 \pm 3.8^{b}$ & * & 6.0 & 15.2 & $11.4 \pm 2.3$ & NS \\
\hline 3HPDA & $<\mathrm{LOQ}^{\mathrm{e}}$ & 18.1 & $4.5 \pm 3.1^{b}$ & $* * *$ & 8.5 & 15.6 & $11.5 \pm 1.9$ & NS \\
\hline
\end{tabular}

Content lower than LOQ in ${ }^{\mathrm{a}} 7,{ }^{\mathrm{c}} 10,{ }^{\mathrm{d}} 8,^{\mathrm{e}} 13$ samples; $^{\mathrm{b}}$ : the mean value was determined using medium-bound approach; SD: standard deviation; NS: $p>0.05 .{ }^{*} p<0.05,{ }^{* *} p<0.01$, $* * * p<0.001$. 
In goat milk, 3HPA was estimated as the most abundant $(41.5 \pm 2.7 \mu \mathrm{g} / \mathrm{mL})$ among the HPAs, followed by 16HPA, 8HPA, 2HPA, 11HPA, and 9HPA in decreasing order, while 10HPA was estimated approximately at $5.8 \pm 1.1 \mu \mathrm{g} / \mathrm{mL}$, and 7HPA was absent from 10 samples. As in cow milk, 7HSA and 10HSA were found again to be the most abundant $(38.2 \pm 8.2 \mu \mathrm{g} / \mathrm{mL}$ and $39.1 \pm 7.2 \mu \mathrm{g} / \mathrm{mL}$, respectively), however at levels not as high as in cow milk. 8HSA was absent from all the samples.

The results highlight a remarkable difference in the contents of 7HSA and 10HSA in cow milk and goat milk. The contents of 7HSA in cow milk (minimum value $38.3 \mu \mathrm{g} / \mathrm{mL}$, maximum value $378.8 \mu \mathrm{g} / \mathrm{mL}$, mean value $175.1 \mu \mathrm{g} / \mathrm{mL}$ ) seem to be substantially higher than those in goat milk (minimum value $21.5 \mu \mathrm{g} / \mathrm{mL}$, maximum value $48.0 \mu \mathrm{g} / \mathrm{mL}$, mean value $38.2 \mu \mathrm{g} / \mathrm{mL}$ ). Thus, 7HSA might be a potential marker to discriminate cow milk from goat milk. The contents of 10HSA in cow milk (minimum value $31.2 \mu \mathrm{g} / \mathrm{mL}$, maximum value $250.1 \mu \mathrm{g} / \mathrm{mL}$, mean value $71.4 \mu \mathrm{g} / \mathrm{mL}$ ), although not presenting such a marked difference, are again higher than those in goat milk (minimum value $18.0 \mu \mathrm{g} / \mathrm{mL}$, maximum value $75.4 \mu \mathrm{g} / \mathrm{mL}$, mean value $39.1 \mu \mathrm{g} / \mathrm{mL}$ ).

Regarding the 3HFAs studied in this work (3HCA, 3HLA, 3HMA, 3HPDA, 3HPA, and 3HSA), all of them were found to be present in goat milk, while 3HCA, 3HLA, 3HMA, and 3HPDA were absent from 8, 7, 8, and 13 milk samples, respectively (Table 4).

Principal Component Analysis (PCA) was performed to explore the relationship between the samples and the data. The results indicated that component PC1 (62.56\%) and component PC2 (14.02\%) were accountable of the total variance and presented Eigen values 18.14 for PC1 and 4.07 for PC2. The Scree plot is depicted in Supplementary Materials (Figure S2). The biplot graph is illustrated in Figure 3. Although a perfect discrimination of both groups of milk samples was not accomplished, a general trend was observed with the majority of cow milk samples to be located at the lower right part of the plot, while the majority of goat milk samples tend to be located at the upper right part of the plot. 7HSA and 11HPA contents (lower right part in the graph) seem to be well correlated with cow milk samples, while 10HSA and 3HPA contents (upper right part in the graph) with goat milk samples.

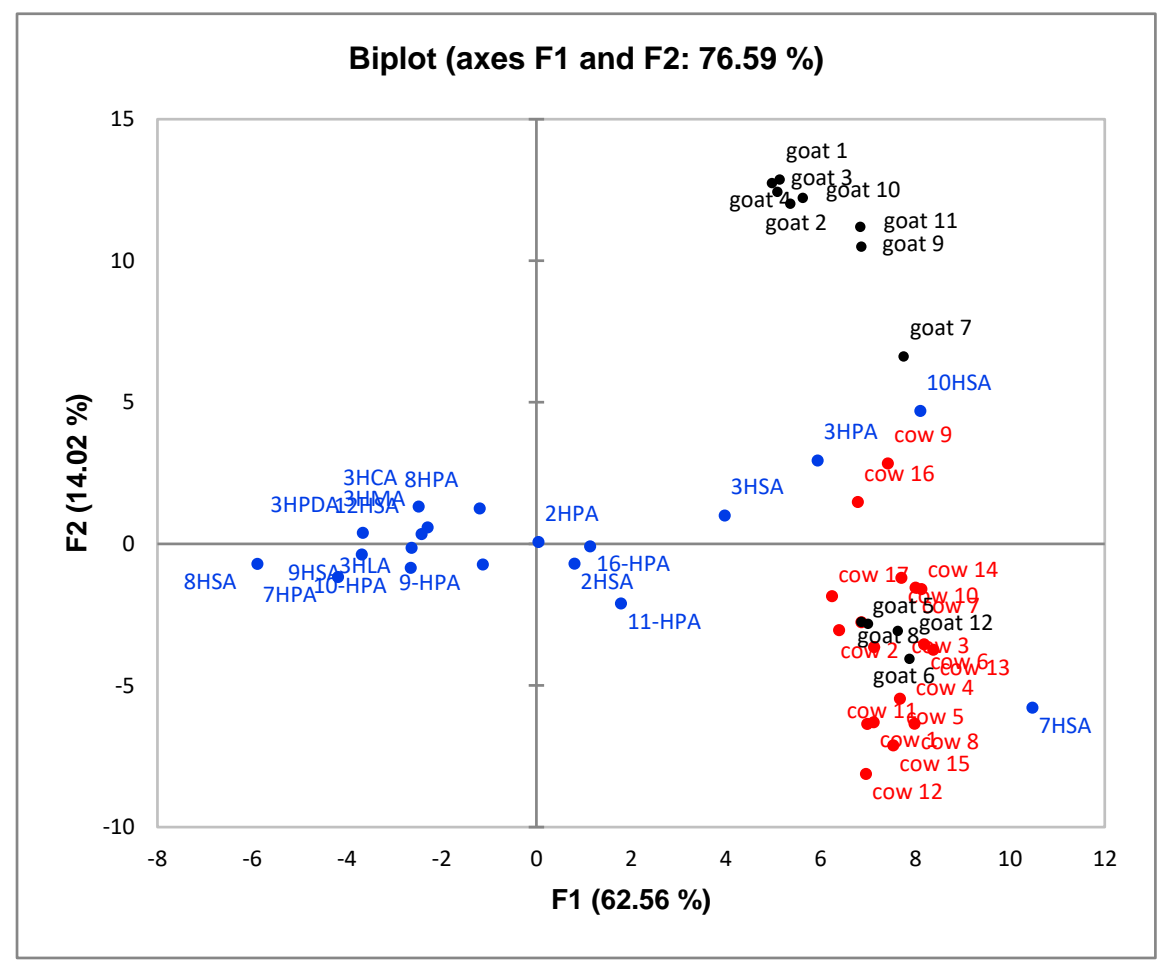

Figure 3. Principal component analysis (PCA) biplot graph of HFAs from cow and goat milk. Active variables (cow red, goat black), active observations (blue). 
The method developed herein allowed us to study for the first time the existence of various hydroxylated positional isomers of palmitic acid and stearic acid in milk and to expand our knowledge on the lipidome of milk. Having on hand a variety of HFAs that previously synthesized by us [26,27], we were able to demonstrate that two families of previously unrecognized HFAs are present in milk, HPAs and HSAs, each one consisting of various members carrying the hydroxyl functionality at different chain positions.

In addition, the simultaneous determination of six free 3HFAs (3HCA, 3HLA, 3HMA, 3HPDA, 3HPA, 3HSA) and two 2HFAs (2HPA and 2HSA) was achieved, following a simple sample preparation protocol. The previous report by Jenske and Vetter referred to the analysis of total 3HFAs and 2HFAs following a tedious sample preparation procedure [19]. The extracted saponifiable lipids were converted into methyl esters, and the resulting FAMEs were separated by chromatography into hydroxy-FAMEs (OH-FAMEs) and non-OH-FAMEs. Then, the OH-FAMEs were converted to pentafluorobenzoyl derivatives and analyzed by gas chromatography with electron capture negative-ion mass spectrometry (GC/ECNI-MS) in the selected ion monitoring (SIM) mode [19] Thus, the present method has clearly the advantage of rapidness and simplicity.

\section{Materials and Methods}

\subsection{Chemicals and Reagents}

All the solvents used were of LC-MS analytical grade. Acetonitrile was purchased from Carlo Erba (Val De Reuil, France), isopropanol and methanol from Fisher Scientific (Laughborough, UK), and formic acid $98-100 \%$ from Chem-Lab (Zedelgem, Belgium). 2HPA and 2HSA were commercially available from Cayman Chemical (Michigan, USA), and 16HPA from Sigma-Aldrich (Darmstadt, Germany). 3HCA, 3HLA, 3HMA, 3HPDA, 3HPA, and 3HSA were synthesized as previously described, and their analytical data were in accordance with the literature [27]. 9HPA, 9HSA, 11HPA, and 12HSA were synthesized as previously described, and their analytical data were in accordance with the literature [26]. 7HPA, 8HPA, 10HPA, 7HSA, 8HSA and 10HSA were synthesized following the general method previously described by us [26] and their details will be presented elsewhere.

\subsection{Stock and Working Solutions}

Stock solutions of the standard compounds $(1000 \mathrm{mg} / \mathrm{L}$ in methanol) were prepared and stored at $4{ }^{\circ} \mathrm{C}$. Working standard solutions $(500 \mathrm{ng} / \mathrm{mL})$ were prepared daily by appropriate dilution.

\subsection{Instrumentation}

Chromatography was performed on a Halo C18 column $(2.7 \mu \mathrm{m}, 90 \AA, 0.5 \times 50 \mathrm{~mm})$ from Eksigent, using a micro-LC Eksigent (Eksigent, Darmstadt, Germany) equipped with an autosampler set at $5{ }^{\circ} \mathrm{C}$ and a thermostated column compartment. Separation was performed with a gradient over the course of $10 \mathrm{~min}$ at a flow rate of $55 \mu \mathrm{L} / \mathrm{min}$, using a mobile phase system consisting of solvent A: acetonitrile/ $0.01 \%$ formic acid/isopropanol $80 / 20 \mathrm{v} / \mathrm{v}$ and solvent $\mathrm{B}: \mathrm{H}_{2} \mathrm{O} / 0.01 \%$ formic acid. The gradient elution program was as follows: $0-0.5 \mathrm{~min}, 5 \% \mathrm{~B} ; 0.5-8.0 \mathrm{~min}$, gradually increasing to $98 \% \mathrm{~B} ; 8.0-8.5 \mathrm{~min}, 98 \% \mathrm{~B}$, followed by a $1.5 \mathrm{~min}$ equilibration step to the initial conditions prior to the next injection. The injection volume was set at $5 \mu \mathrm{L}$.

An ABSciex Triple TOF 4600 (ABSciex, Darmstadt, Germany) was used to perform the HRMS measurements and all the experiments were carried out by ESI in negative mode. The data acquisition method consisted of a TOF-MS full scan $\mathrm{m} / \mathrm{z} 50-850$ and several information-dependent acquisition (IDA)-TOF-MS/MS product ion scans, using a $40 \mathrm{~V}$ collision energy (CE), with a $15 \mathrm{~V}$ collision energy spread (CES) used for each candidate ion in each data acquisition cycle (1091). The MS resolution working conditions were: ion energy 1 (IE1) -2.3 , vertical steering (VS1) -0.65 , horizontal steering (HST) 1.15, and vertical steering 2 (VS2) 0.00. MultiQuant 3.0.2 and PeakView 2.1 (ABSciex, Darmstadt, Germany) were employed for the data acquisition. EICs were obtained creating the base peak 
chromatograms for masses that achieve a 0.01 Da mass accuracy width. The relative tolerance of the retention time was set within a margin of $\pm 2.5 \%$.

\subsection{Sample Preparation}

Methanol $(4 \mathrm{~mL})$ was added to the milk sample $(1 \mathrm{~mL})$ in a screw cap glass centrifuge tube. After stirring for about $30 \mathrm{~s}$, the sample was centrifuged at $4000 \times g$ for $10 \mathrm{~min}$. The supernatant $(500 \mu \mathrm{L})$ was then mixed with $500 \mu \mathrm{L}$ of water in a vial, and this mixture was used for the LC-MS/MS analysis.

\subsection{Method Validation}

Solutions from 5-800 ng/mL of 2HPA, 3HPA, 7HPA, 8HPA, 9HPA, 10HPA, 11HPA, 16HPA, 2HSA, 3HSA, 7HSA, 8HSA, 9HSA, 10HSA, 12HSA, 3HCA, 3HLA, 3HMA, and 3HPDA (3 replicates; 13 levels $(5,10,30,50,80,100,200,300,400,500,600,700,800 \mathrm{ng} / \mathrm{mL}) ; n=3 \times 13)$ were used to assess the linearity and the limits of detection (LOD) and quantification (LOQ). The LOD and LOQ were calculated using the signal-to-noise method. A signal-to-noise ratio $(\mathrm{S} / \mathrm{N})$ of three is generally accepted for estimating the LOD, and a signal-to-noise ratio of 10 is used for estimating the LOQ. This method is commonly applied to analytical methods that exhibit baseline noise.

Cow milk samples were spiked at three different concentration levels to estimate the recovery and the intra-day and inter-day variations. The recovery was used for the quantification of the selected compounds in milk.

\subsection{Milk Samples}

Twenty-nine brand products of fresh (pasteurized) whole milk were collected from the local market in Athens, Greece. Seventeen of them were cow milk products, and 12 of them were goat milk products.

\subsection{Statistical Analysis}

Level of significance was estimated using Excel t-Test: two-sample assuming unequal variances. Principal Component Analysis (PCA) was performed using XLSTAT (2018).

\section{Conclusions}

In conclusion, we demonstrate herein for the first time a method for the determination of various free HFAs, including palmitic and stearic acids carrying the hydroxyl group at different positions, in cow and goat milk. Our LC/HRMS method involves mild sample preparation conditions, avoids time-consuming extraction pre-separation or derivatization procedures, and permits the quantification of 19 free HFAs in a single 10-min run. Using this rapid and robust method, various previously unrecognized hydroxylated palmitic and stearic acids were identified both in cow and in goat milk. The most abundant HFAs in cow milk were proven to be 7HSA and 10HSA (mean content values of $175.1 \pm 3.4 \mu \mathrm{g} / \mathrm{mL}$ and $72.4 \pm 6.1 \mu \mathrm{g} / \mathrm{mL}$ in fresh milk, respectively). The contents of $7 \mathrm{HSA}$ in cow milk seem to be substantially higher than those in goat milk, and thus 7HSA might be a potential marker to discriminate cow milk from goat milk. Given that HFAs are an emerging class of bioactive lipids, the present method is of particular interest in identifying novel lipids that may play a role in human health.

Supplementary Materials: The following are available online at http://www.mdpi.com/1420-3049/25/17/3947/s1: Figure S1: MS/MS spectra of 2HPA (A), 3HPA (B), 7HPA (C), 8HPA (D), 9HPA (E), 10HPA (F), 11HPA (G), 16HPA $(\mathrm{H})$, 2HSA (I), 3HSA (J), 7HSA (K), 8HSA (L), 9HSA (M), 10HSA (N), 12HSA (O), 3HCA (P), 3HLA (Q), 3HMA (R) and 3HPDA (S), Figure S2: Principal component analysis (PCA) Scree plot of HFAs from cow and goat milk.

Author Contributions: Conceptualization, G.K.; methodology, M.G.K. and C.M.; synthesis of compound, A.B. and O.G.M.; software, M.G.K. and C.M.; writing-review and editing, M.G.K and G.K. All authors have read and agreed to the published version of the manuscript. 
Funding: The research presented was carried out within the framework of a Stavros Niarchos Foundation grant to the National and Kapodistrian University of Athens. The research work was supported by the Hellenic Foundation for Research and Innovation (HFRI) under the HFRI PhD Fellowship grant (Fellowship Number: 1338) (O.G.M).

Conflicts of Interest: The authors declare no conflict of interest.

\section{References}

1. Jensen, R.G. The composition of bovine milk lipids: January 1995 to December 2000. J. Dairy Sci. 2002, 85, 295-350. [CrossRef]

2. German, J.B.; Dillard, C.J. Composition structure and absorption of milk lipids: A source of energy, fat-soluble nutrients and bioactive molecules. Crit. Rev. Food Sci. Nutr. 2006, 46, 57-92. [CrossRef] [PubMed]

3. Liu, Z.; Li, C.; Pryce, J.; Rochfort, S. Comprehensive characterization of bovine milk lipids: Triglycerides. Acs Omega 2020, 5, 12573-12582. [CrossRef] [PubMed]

4. Antonelli, M.L.; Curini, R.; Scricciolo, D.; Vinci, G. Determination of free fatty acids and lipase activity in milk: Quality and storage markers. Talanta 2002, 58, 561-568. [CrossRef]

5. Lindmark Mansson, H. Fatty acids in bovine milk fat. Food Nutr. Res. 2008, 52. [CrossRef]

6. Amores, G.; Virto, M. Total and free fatty acids analysis in milk and dairy fat. Separations 2019, 6, 14. [CrossRef]

7. Alonso, L.; Fontecha, J.; Lozada, L.; Fraga, M.J.; Juarez, M. Fatty acid composition of caprine milk: Major, branched-chain, and trans fatty acids. J. Dairy Sci. 1999, 82, 878-884. [CrossRef]

8. Ceballos, L.S.; Morales, E.R.; Adarve, G.T.; Castro, J.D.; Martinez, L.P.; Sampelayo, M.R.S. Composition of goat and cow milk produced under similar conditions and analyzed by identical methodology. J. Food Compos. Anal. 2009, 22, 322-329. [CrossRef]

9. Gómez-Cortés, P.; Juárez, M.; Angel de la Fuente, M. Milk fatty acids and potential health benefits: An updated vision. Trends Food Sci. Technol. 2018, 81, 1-9. [CrossRef]

10. Guo, J.; Astrup, A.; Lovegrove, J.A.; Gijsbers, L.; Givens, D.I.; Soedamah-Muthu, S.S. Milk and dairy consumption and risk of cardiovascular diseases and all-cause mortality: Dose-response meta-analysis of prospective cohort studies. Eur. J. Epidemiol. 2017, 32, 269-287. [CrossRef]

11. Lovegrove, J.A.; Givens, D.I. Dairy food products: Good or bad for cardiometabolic disease? Nutr. Res. Rev. 2016, 29, 249-267. [CrossRef] [PubMed]

12. Forouhi, N.G.; Krauss, R.M.; Taubes, G.; Willett, W. Dietary fat and cardiometabolic health: Evidence, controversies, and consensus for guidance. BMJ 2018, 361, k2139. [CrossRef]

13. Astrup, A.; Bertram, H.C.S.; Bonjour, J.-P.; de Groot, L.C.P.; de Oliveira Otto, M.C.; Feeney, E.L.; Garg, M.L.; Givens, I.; Kok, F.J.; Krauss, R.M.; et al. WHO draft guidelines on dietary saturated and trans fatty acids: Time for a new approach? BMJ 2019, 366, 14137. [CrossRef]

14. Imamura, F.; Fretts, A.; Marklund, M.; Ardisson Korat, A.V.; Yang, W.-S.; Lankinen, M.; Qureshi, W.; Helmer, C.; Chen, T.-A.; Wong, K.; et al. Fatty acid biomarkers of dairy fat consumption and incidence of type 2 diabetes: A pooled analysis of prospective cohort studies. PLoS Med. 2018, 15, e1002670. [CrossRef] [PubMed]

15. Mannion, D.T.; Furey, A.; Kilcawley, K.N. Free fatty acids quantification in dairy products. Int. J. Dairy Technol. 2016, 69, 1-12. [CrossRef]

16. La Nasa, J.; Degano, I.; Brandolini, L.; Modugno, F.; Bonaduce, I. A novel HPLC-ESI-Q-ToF approach for the determination of fatty acids and acylglycerols in food samples. Anal. Chim. Acta 2018, 1013, 98-109. [CrossRef] [PubMed]

17. Kokotou, M.G.; Mantzourani, C.; Kokotos, G. Development of a liquid chromatography-high resolution mass spectrometry method for the determination of free fatty acids in milk. Molecules 2020, 25, 1548. [CrossRef] [PubMed]

18. Jenske, R.; Vetter, W.J. Enantioselective analysis of 2- and 3-hydroxy fatty acids in food samples. J. Agric. Food Chem. 2008, 56, 11578-11583. [CrossRef]

19. Jenske, R.; Vetter, W. Concentrations of medium-chain 2- and 3-hydroxy fatty acids in foodstuffs. Food Chem. 2009, 114, 1122-1129. [CrossRef] 
20. Márquez-Ruiz, G.; Rodríguez-Pino, V.; de la Fuente, M.A. Determination of 10-hydroxystearic, 10-ketostearic, 8-hydroxypalmitic, and 8- ketopalmitic acids in milk fat by solid-phase extraction plus gas chromatography-mass spectrometry. J. Dairy Sci. 2011, 94, 4810-4819. [CrossRef]

21. Yore, M.M.; Syed, I.; Moraes-Vieira, P.M.; Zhang, T.; Herman, M.A.; Homan, M.A.; Patel, R.T.; Lee, J.; Chen, S.; Peroni, O.D.; et al. Discovery of a class of endogenous mammalian lipids with anti-diabetic and anti-inflammatory effects. Cell 2014, 159, 318-332. [CrossRef] [PubMed]

22. Moraes-Vieira, P.M.; Saghatelian, A.; Kahn, B.B. GLUT4 Expression in adipocytes regulates de novo lipogenesis and levels of a novel class of lipids with antidiabetic and anti-inflammatory effects. Diabetes 2016, 65, 1808-1815. [CrossRef] [PubMed]

23. Kuda, O.; Brezinova, M.; Rombaldova, M.; Slavikova, B.; Posta, M.; Beier, P.; Janovska, P.; Veleba, J.; Kopecky, J., Jr.; Kudova, E.; et al. Docosahexaenoic acid-derived fatty acid esters of hydroxy fatty acids (FAHFAs) with anti-inflammatory properties. Diabetes 2016, 65, 2580-2590. [CrossRef] [PubMed]

24. Calonghi, N.; Cappadone, C.; Pagnotta, E.; Boga, C.; Bertucci, C.; Fiori, J.; Tasco, G.; Casadio, R.; Masotti, L. Histone deacetylase 1: A target of 9-hydroxystearic acid in the inhibition of cell growth in human colon cancer. J. Lipid Res. 2005, 46, 1596-1603. [CrossRef]

25. Albadri, S.; Naso, F.; Thauvin, M.; Gauron, C.; Parolin, C.; Duroure, K.; Vougny, J.; Fiori, J.; Boga, C.; Vriz, S.; et al. Redox signaling via lipid peroxidation regulates retinal progenitor cell differentiation. Dev. Cell 2019, 50, 73-89. [CrossRef]

26. Mountanea, O.G.; Limnios, D.; Kokotou, M.G.; Bourboula, A.; Kokotos, G. Asymmetric synthesis of saturated hydroxy fatty acids and fatty acid esters of hydroxy fatty acids. Eur. J. Org. Chem. 2019, 10, 2010-2019. [CrossRef]

27. Bourboula, A.; Limnios, D.; Kokotou, M.G.; Mountanea, O.G.; Kokotos, G. Enantioselective organocatalysis-based synthesis of 3-hydroxy fatty acids and fatty $\gamma$-lactones. Molecules 2019, $24,2081$. [CrossRef] [PubMed]

28. Hill, H.M.; Bakes, D.; Love, I. Manual chromatographic baseline integration: Is it needed, if so when should it be used? Bioanalysis 2014, 6, 1171-1174. [CrossRef]

Sample Availability: Sample Availability: Not applicable.

(C) 2020 by the authors. Licensee MDPI, Basel, Switzerland. This article is an open access article distributed under the terms and conditions of the Creative Commons Attribution (CC BY) license (http://creativecommons.org/licenses/by/4.0/). 